\title{
Radiochemical Applications in Industry - A Journey through Time with RC Tritec
}

\author{
Albert Zeller*, Nando Gartmann, and Thomas Zeltner
}

\begin{abstract}
Over the course of time, radioactive applications have changed from miracle cures to a material that is treated with caution in public perception. As a Swiss company, which has always been working with radioactive materials, RC Tritec is an interesting example how the applications in private industry have changed over the years: The company was originally a Ra-226 activated luminous paint manufacturer which managed to become a leader in the field of tritium labelling, the construction of manifolds for the handling of ionizing gases, source production and neutron imaging.
\end{abstract}

Keywords: Gas handling · Neutron imaging · Persistent luminescence $\cdot$ Radium-226 · Tritium labeling

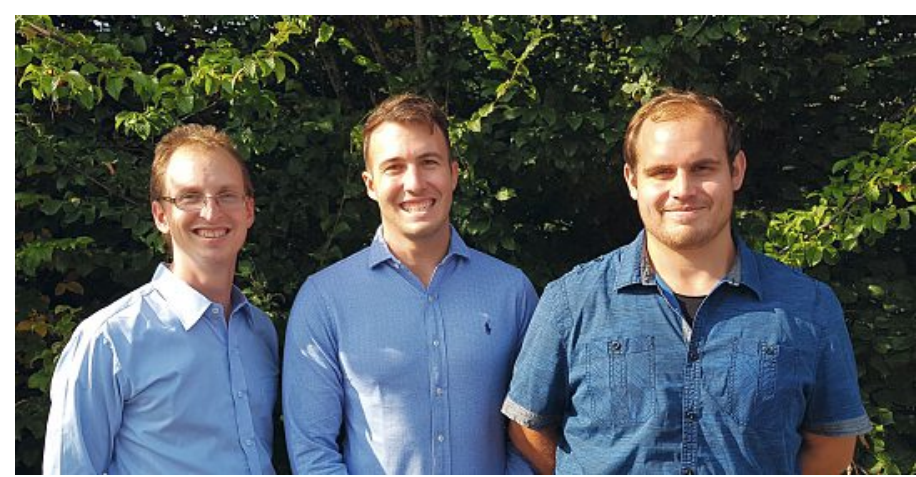

Albert Zeller was born in 1988 in St. Gallen, Switzerland and grew up in Teufen. He holds a BSc and MSc degree in Chemistry and Business Studies from the University of Zürich and has a DAS in SME Management (University St. Gallen). Albert is CEO of RC Tritec, a manufacturer of luminous pigments for the Swiss watch industry since the beginning of 2017.

Nando Gartmann was born in 1983 in Chur, where he also grew up. After finishing his Matura he studied Chemistry at the University of Zürich where he graduated with a $\mathrm{PhD}$ degree in in the end of 2012. Ever since then he has been working at RC Tritec where he is the responsible for the luminous pigment production as well as head of radioprotection and radioactive waste processing.

Thomas Zeltner finished his apprenticeship as a laboratory technician in 2013 at the University Bern in the Department of Chemistry and Biochemistry. Afterwards he studied chemistry at the ZHAW in Wädenswil where he finished his Bachelor and Master's degree at the Riedl Lab working on the development of novel antibiotics. Since August 2020 he is working in the tritium labeling branch at RC Tritec in Teufen.

\section{RC Tritec through the Ages}

RC Tritec is a typical Swiss small and medium enterprise (SME), led by the fourth generation of owners and situated in Teufen, Switzerland. RC Tritec was founded under the name Radium Chemie Zeller in 1934. Since then, radiochemical applications and their perception with the general public have changed a lot.

Originally starting with ${ }^{226} \mathrm{Ra}$ applications, RC Tritec has developed itself to become a leader in persistent luminescent pigments, handling of tritium and offers solutions in the field of neutron imaging and the disposal of radioactive waste.

With a strong focus on research and development, RC Tritec is in partnership with leading research institutes such as PSI, University of Geneva and EMPA. This offers the possibility to expand the internal research onto fundamental research of the handled materials.

\section{2. ${ }^{226} \mathrm{Ra}$ - From a Miracle Cure to Danger}

When Pierre and Marie Curie measured the activity of pitchblende and compared it to pure uranium salts, they realized that it was much higher than expected. It was concluded that pitchblende must contain other elements featuring stronger radioactivity than uranium. Upon separation of pitchblende into different fractions first the radioactive polonium and later ${ }^{226} \mathrm{Ra}$ were found.

After its discovery in 1898 by Pierre and Marie Curie and Gustave Bémont, ${ }^{[1]}{ }^{226} \mathrm{Ra}$ was first regarded as rather harmless or even as healthy. In the years after, many new products containing ${ }^{226} \mathrm{Ra}$ entered the market. Among such products were drinking cures (Fig. 1), toothpastes or ${ }^{226} \mathrm{Ra}$-containing skin moisturizers.

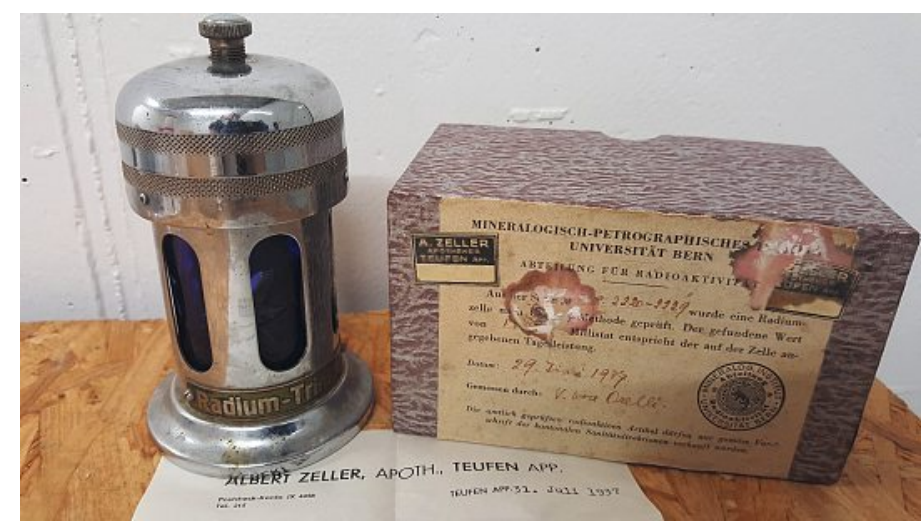

Fig. 1. Radium drinking cure 
Later, various manufacturers of $\mathrm{ZnS}$ doped with copper appeared on the Swiss market: This combination of zinc sulfide with ${ }^{226} \mathrm{Ra}$ created a persistent luminescent material, which was used to make watch hands and dials visible in the dark.

A mixture of those pigments with a binder was used to apply these materials mainly by brush onto watch components. This is also where the problem in the application itself lay: The people who applied these mixtures onto the components were in very close contact with the strongly emitting ${ }^{226} \mathrm{Ra}$ and sometimes even swallowed the paint, while resharpening the brushes with their tongues. As a consequence to this, several cases of illnesses in the area of the mouth and throat were observed. ${ }^{[2]}$

When the threat of ${ }^{226} \mathrm{Ra}$ in luminous paint became more and more clear, the founder Albert M. Zeller and his son Albert E. Zeller decided to look for a less harmful alternative: The application of ${ }^{226} \mathrm{Ra}$ did not have a very promising future for consumer goods such as watches, but it was the best performing material available on the market. Copper-doped zinc sulfide remained the luminous crystallites, but the harmful activator had to be exchanged. A gaseous isotope with a comparable rather low $\beta$-emission energy of max. $18.6 \mathrm{keV}$, tritium, showed the exact specifications that the chemists in Teufen were looking for.

\section{Tritium - A 'Healthy Alternative'}

At the end of the $1950 \mathrm{~s}$, it became clear that ${ }^{226} \mathrm{Ra}$ activated phosphorescent paints were extremely critical, especially in the manufacturing process ('radium girls'). With the availability of tritium on the non-military market at the end of the 1950s, attempts began to use tritium, a very weak and pure $\beta$-emitter, to produce a 'harmless' luminous paint.

Initial attempts to convert the gas into a stable compound by hydrogenation of unsaturated fatty acids in order to coat zinc sulfide crystals and to excite them to glow permanently by beta radiation failed. These compounds were unstable due to the relatively high required specific activity $(10-100 \mathrm{Ci} / \mathrm{g})$, underwent radiolysis and exchanged very quickly with the ambient air.

The company Radium-Chemie Teufen (later RC Tritec) developed a synthesis to form a stable polymer: Styrene was produced by tritiation of phenylacetylene. This was polymerized in substance with stabilizing copolymers (Scheme 1). The T-copolymer was dissolved and coated on $\mathrm{ZnS}$ crystals.

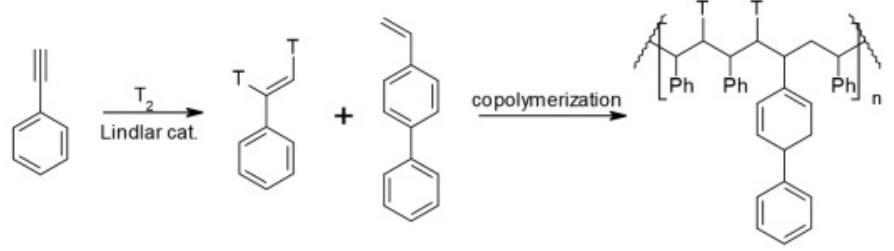

Scheme 1. Schematic representation of tritiated styrene production.

Despite the necessary high specific activity of up to $400 \mathrm{Ci} / \mathrm{g}$, a quite stable luminous paint with a practical brightness half-life of about 5 years could be produced. The reduced practical half-life of the phosphorescent paint compared to the physical half-life of tritium with 12.3 years was based on damage to the $\mathrm{ZnS}$ crystals, radiolysis of the polymer by radical formation and isotope exchange with the ambient humidity. With this quite stable tritium luminous paint the approval of the USNRC (US Nuclear Regulatory Commission) could be achieved in 1962. Within a very short time, the Swiss and European watch industry also switched to the new 'harmless' and 'radiation-free' luminous paint, as no radiation could be measured on the outside of a watch. Nowadays tritiumpowered light sources are only still used in military applications, consisting of sealed glass pipes containing ${ }^{3} \mathrm{H}$ gas with a $\mathrm{ZnS}$ coating on the inside of the glass. Such 'Gaseous Tritium Light
Sources' are still produced in Switzerland by MB Microtec AG in Niederwangen and by Smolsys ltd. in Root.

\section{Changes in Technologies Mean Chances - RC Tritec Today}

By the end of the 1980s, during the big Swatch boom, the image of radioactive applications had suffered a lot in public. On the one hand, the nuclear arms race between East and West and on the other hand also accidents in nuclear reactors like the one in Chernobyl had frightened people. Even though tritium could not be measured outside of a watch luminized with tritium-activated zinc sulfides, some people were afraid of the radioactive material in their watches.

Therefore, Albert R. Zeller, the third-generation owner of RC Tritec, decided to analyze an alternative luminous material, which he received a few years before in China. The structure was $\mathrm{SrAl}_{2} \mathrm{O}_{4}$ doped with $\mathrm{Eu}^{2+}$. Since this material has a Mohs hardness of 9 it was never before analyzed, because it was too hard to handle and very abrasive compared to the zinc sulfide.

Albert R. Zeller handed over the material to a long-term partner company in Japan called Nemoto\&Co., Ltd. which did further analysis on it. While examining the material in Japan, it was found out, that by co-doping of the crystal structure with $\mathrm{Dy}^{3+}$, the luminous performance could be significantly increased..$^{[3]}$

Nemoto launched a patent on this novel persistent luminescent material ${ }^{[4]}$ and it was decided to found a joint-venture company called LumiNova Ltd. Switzerland to satisfy the needs of the Swiss watch industry to have a $100 \%$ Swiss-made luminous pigment. Nowadays, all of the luminous pigments which glow on Swissmade watches are produced in Teufen, serving the entire scale from affordable daily-use watches to the highest price segment.

\section{Swiss Super-LumiNova ${ }^{\circledR}$}

The brand name of this persistent luminescent material is 'Swiss Super-LumiNova ${ }^{\circledR}$ '. It is available in minimum order quantities of $1 \mathrm{~g}$ upwards. $1 \mathrm{~g}$ may not seem to be a huge quantity, but it is enough to luminize a few hundred watch dials. Therefore, the quality of the pigment itself also has to fulfill the demands of the watch industry. Parameters like granulometry, fluorescence, body color, chargeability and luminous decay are all measured in a triple quality control to avoid problems for the dial and hand producers.

Since its discovery in $1996^{[3]}$ many different models for the afterglow mechanism have been proposed..$^{[5-9]}$ Despite extensive research of many scientists, so far none of the proposed mechanisms can explain all experimental findings of the last 25 years, and the true mechanism remains to be found. It is mostly agreed upon that under illumination of the materials, electrons from the excited europium ions are transferred to and caught in different so-called trap-states. These electrons are then thermally liberated over many hours to recombine with the europium centers and emit light.

Research and development to increase the quality and performance of existing materials or to even find better performing phosphors is a very crucial point for RC Tritec. Since not all the developments can be done in-house, strong partnerships with universities and research institutes worldwide were established: The University of Geneva and EMPA are two such partners. Our partners offer access to large amounts of specialized know-how and big scientific measurement devices.

\section{Neutron Detector Screens}

As a combination of the know-how in luminous pigments and radioactive applications the field of scintillator screens for neutron imaging is a perfect supplement to the established portfolio.

It was shown in the past years that neutron imaging has become a powerful, competitive and promising method for mate- 
rial research, many industrial applications and a tool for different branches in university-related studies.[10,11] One main reason for the progress is given by the development and application of dedicated digital neutron imaging devices in combination with scintillator screens as the backbone of the detector system. Using scintillation screens the exposure time has been reduced from hours to seconds and nowadays even down to the micro-second scale. Therefore it is obvious that the performance of the scintillator screen directly influences the performance of a NI beamline.

Depending on the neutron energy (cold/thermal or fast neutrons) different two-step scintillation mechanisms occur. In the case of thermal neutrons, first a core reaction process $\left(\right.$ in ${ }^{6} \mathrm{Li},{ }^{10} \mathrm{~B}$, ${ }^{3} \mathrm{He}$ or $\mathrm{Gd}$ ) is used. This does not work for fast neutrons due to the lack of strong neutron absorbers. In this case the creation of recoil protons by the collision of neutrons at hydrogen is one of the most efficient processes for the neutron detection process. ${ }^{[12]}$ These secondary radiations are utilized to excite the scintillating material like $\mathrm{ZnS}: \mathrm{Cu}$ or $\mathrm{Gd}_{2} \mathrm{O}_{2} \mathrm{~S}: \mathrm{Tb}$ and others.

In collaboration with the Paul Scherrer Institute, RC Tritec AG has developed different kinds of scintillation screens, which are used in most prominent beam lines for material analyses.

\section{7. ${ }^{3} \mathrm{H}$-Labeling Service}

Since styrene had already been tritiated some years before for the application of luminous pigments, the know-how was transferred to the pharmaceutical field, where it is nowadays used for the labeling of interesting compounds with tritium.

The common source of the tritium label is tritium gas which needs to be incorporated into a target molecule by special preparation techniques.

For the preparation of tritium-labelled compounds a broad spectrum of reaction types is available. While classical labelling strategies like double bond reduction, hydride reduction and tritium halogen exchange still remain in use they have been significantly improved over the last 30 years. The use of chiral hydrides enables enantioselective reduction, whereas advanced knowledge about the selectivity of dehalogenation reactions enables iodine or bromine/tritium exchange in presence of other halogens (Scheme 2). ${ }^{[13-15]}$
Tritium-labelled compounds have a variety of applications in receptor studies. They are used to characterize receptors, study their dynamics or to define ligand activity, just to name a few. High throughput screening is enabled by homogenous scintillation proximity assays, where the receptor is bound on the surface of a scintillant beat. Because the distance of $\beta$-particles emitted by tritium is limited to about $8 \mu \mathrm{m}$ in aqueous media, only receptorbound ligands are in close enough range to activate the scintillant and cause a signal in form of light. $[16,18,19]$

Additionally radioactive isotopes like ${ }^{3} \mathrm{H}$ and ${ }^{14} \mathrm{C}$ are often used in adsorption, distribution, metabolism and excretion (ADME). Tritium-labelled compounds allow the early evaluation of reactive metabolite formation and provide relevant information on metabolic pathways of new chemical entities. ${ }^{[16]}$ Furthermore the distribution of drugs in different tissues can be tested by quantitative autoradiography determining the drug level in different tissue sections. ${ }^{[13]}$

Handling of tritium- or ${ }^{14} \mathrm{CO}_{2}$-gases has to take place in high vacuum systems (Fig. 2), which can go down to a pressure of $10^{-8}$ mbar. Such systems are produced in-house in Teufen and delivered to the international market.

\section{Production of lonizing Sources}

Industrial applications of radiochemical isotopes also include the production of sealed radioactive sources. Such sources allow the handling of radioactivity with a very low risk of contamination.

Small sealed sources with a variety of nuclides are produced by $\mathrm{RC}$ Tritec in custom designs in Teufen. These sources are used in many industrial applications, e.g. ${ }^{147} \mathrm{Pm},{ }^{204} \mathrm{Tl}$ and ${ }^{90} \mathrm{Sr}$ point sources are used to measure coating thicknesses by betabackscattering in the automotive industry, electronics industry, coating technologies and many others. ${ }^{14} \mathrm{C}$ sources are used for the measurement of air pollution. Further isotopes that are often used in small sealed sources are ${ }^{85} \mathrm{Kr}$ for the measurement of paper thickness and ${ }^{63} \mathrm{Ni}$ in electron capture detectors which are coupled to gas chromatographs for use in environmental analysis for the detection of sulfurous, halogenated and nitrated compounds. ${ }^{[20,21]}$
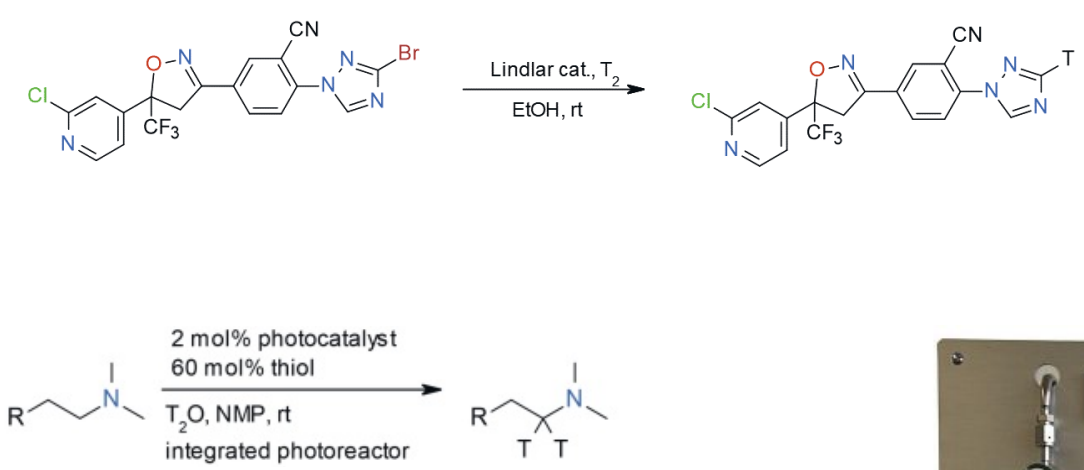

Scheme 3. Direct HIE using photocatalyst to activate the $\mathrm{CH}$-sp3 bond.

Another powerful tool in tritium labelling are direct hydrogen isotope exchange (HIE) reactions, where tritium can be directly incorporated into the target molecule, what saves cost and time intensive precursor synthesis. Most of these HIE reactions depend on a heterogeneous or homogenous catalyst (Scheme 3 ) but also base or acid-mediated reaction types are known. ${ }^{[16,17]}$

\subsection{Use of Tritium}

Tritium is a widely used radioactive tracer element, due to its favorable properties. The $\beta$-particles emitted from tritium are not able to pass solid media, while their energy is high enough to make measurement with liquid scintillation counting possible.
Scheme 2. Selective dehalogenation of bromine in presence of a chlorine using Lindlar catalystmediated halogen/tritium exchange.

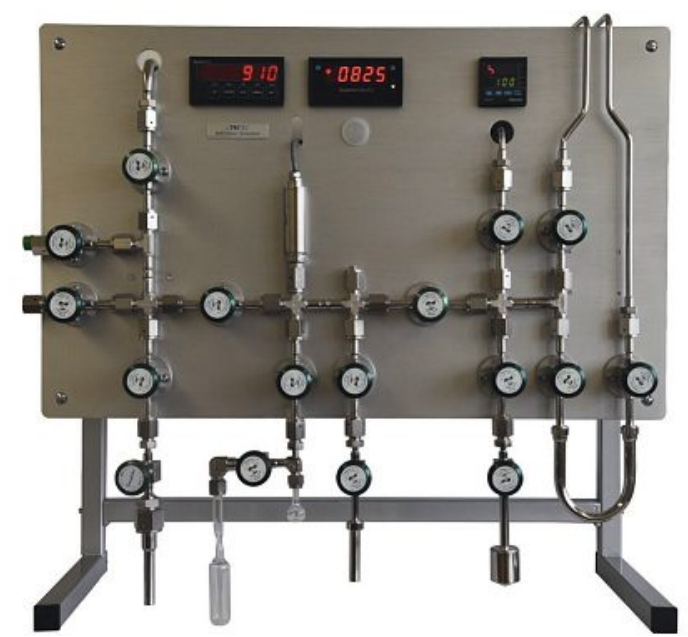

Fig. 2. High vacuum manifold system used for tritium labeling of organic molecules. 
Historically, sealed ${ }^{226} \mathrm{Ra}$ or ${ }^{241} \mathrm{Am}$ sources have also been applied in smoke detectors produced by the renowned Cerberus AG in Bad Ragaz and Männedorf.

Highly active sealed radioactive sources are mainly used in medical applications and industrial radiography, e.g. with ${ }^{192} \mathrm{Ir}$.

\section{Decontamination and Disposal of Radioactive Waste Materials}

Preparation of industrial radioactive products often leads to radioactive waste as an unwanted byproduct. As a result of the treatment of the internal volatile radioactive waste and the good relationship with the responsible authorities and the PSI, safe processes for the treatment of certain radioactive waste products could be developed. RC Tritec therefore also has the possibilities to offer a waste treatment and decontamination service for the medicine, industry and research sector, and prepare these waste for final disposal.

\section{Conclusion}

Many radioactive applications have receded into the background over the last century and have been replaced by non-radioactive alternatives, yet radioactivity remains an important issue for mankind.

Even if radioactivity may not have the best reputation among the general public, its applications remain indispensable. It is therefore important not to close one's eyes to the positive aspects and to continue to explore this energy with its applications and to create a benefit for the well-being of mankind. With its many world-leading research institutes, Switzerland offers an ideal framework for research and development in this highly interesting field.

\section{Acknowledgements}

We would like to thank Prof. Dr. Roger Alberto for giving us the possibility to present our company history and research in CHIMIA. He accompanied us during our studies and it is a great pleasure to also maintain the contact in the industrial world with him.

Furthermore, we would also like to thank Albert R. Zeller for taking his time to teach us more about the history of RC Tritec and always being open to share his deep knowledge about industrial applications in the field of radioactivity with us.
[1] P. Curie, M. Curie, G. Bémont, Comptes rendus hebdomadaires des séances de l'Académie des sciences 1898, 127, 1215.

[2] H. S. Martland, R. E. Humphries, Arch. Pathol. 1929, 5, 406.

[3] T. Matsuzawa, Y. Aoki, N. Takeuchi, Y, Murayama, J. Electrochem. Soc. 1996, 143, 2670.

[4] Y. Aoki, T. Matsuzawa, Y. Murayam, N. Takeuchi, Patent: EP0622440B2.

[5] H. Yamamoto, T. Matsuzawa, J. Lumines. 1997, 72-74, 287.

[6] T. Aitasalo, P. Deren, J. Hölsä, H. Jungner, J.C. Krupa, M. Lastusaari, J. Legendziewicz, J. Niittykoski, W. Strek, J. Solid State Chem. 2003, 171, 114.

[7] P. Dorenbos, J. Electrochem. Soc. 2005, 152, 107.

[8] F. Clabau, X. Rocquefelte, S. Jobic, P. Deniard, M.H. Whangbo, A. Garcia, T. Le Mercier, Chem. Mat. 2005, 17, 3904.

[9] J. J. Joos, K. Korthout, L. Amidani, P. Glatzel, D. Poelman, P. F. Smet, Phys. Rev. Lett. 2020, 125, 033001.

[10] E. H. Lehmann, P. Vontobel, G. Frei, C. Brönnimann, Nucl. Instr. Meth. Phys. Res. A 2004, 531, 228.

[11] N. Kardjilov, I. Manke, R. Woracek, A. Hilger, J. Banhart, Mater. Today 2018, 21,652 .

[12] M. G. Makowska, B. Walfort, A. Zeller, C. Grünzweig, T. Bücherl, J. Imaging 2017, 3, 60 .

[13] W. J. S. Lockley, A. McEwen, R. Cooke, J. Label. Compd. Radiopharm. 2012, $55,235$.

[14] M. Saljoughian, Synthesis 2002, 13, 1781.

[15] J. J. Rauh, G. P. Lahm, T. F. Pahutski, G. . Ullas, C. N. Filer, J. Label. Compd. Radiopharm. 2010, 53, 50

[16] J. Atzrodt, V. Derdau, W. J. Kerr, M. Reid, Angew. Chem. Int. Ed. 2018, 57, 1758.

[17] M. Valero, D. Becker, K. Jess, R. Weck, J. Atzrodt, T. Bannenberg, V. Derdau, M. Tamm, Chem. Eur. J. 2019, 25, 6517.

[18] N. D. Cook, Drug Discov. Today 1996, 1, 287.

[19] P. Hein, M.C. Michel, K. Leineweber, T. Wieland, N. Wettschureck, S. Offermanns, in 'Practical Methods in Cardiovascular Research', Eds. S. Dhein, F.W. Mohr, M. Delmar, Springer, Berlin, Heidelberg. 2005, pp. 723783

[20] J. E. Lovelock, J. Chromatogr. A 1958, 1, 35.

[21] J. E. Lovelock, J. Chromatogr. A 1958, 99, 3.

\section{License and Terms}

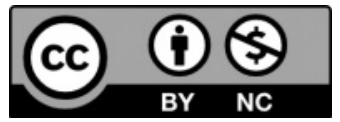

This is an Open Access article under the terms of the Creative Commons Attribution License CC BY_NC 4.0. The material may not be used for commercial purposes.

The license is subject to the CHIMIA terms and conditions: (http:// chimia.ch/component/sppagebuilder/?view=page \&id=12).

The definitive version of this article is the electronic one that can be found at https://doi.org/10.2533/chimia.2020.1015 